\title{
Role of Community Radio for Community Development in Bangladesh
}

\author{
Md. Anowarul Arif Khan ${ }^{1}$ \\ Access to Information (a2i), Prime Minister's Office, Bangladesh \\ Email: anowarularif.a2i@gmail.com \\ Md. Mostafizur Rahman Khan ${ }^{2}$ \\ Access to Information (a2i), Prime Minister's Office, Bangladesh \\ Email: mostafiz.a2i@gmail.com \\ Mahmudul Hassan ${ }^{3}$ \\ Access to Information (a2i), Prime Minister's Office, Bangladesh \\ Email: mahmud.rm.a2i@gmail.com \\ Firoz Ahmed ${ }^{4}$ \\ Access to Information (a2i), Prime Minister's Office, Bangladesh \\ Email: firozanthro10@gmail.com \\ Shah Md. Rauful Haque 5 \\ Access to Information (a2i), Prime Minister's Office, Bangladesh \\ Email:smraufulhq@gmail.com
}

\begin{abstract}
Community radio is a medium of expressing and sharing views, thoughts, ideas, problems and prospects of rural, disadvantaged, vulnerable and hard to reach population with the mainstream population. As the media of root level people of the disadvantaged areas, Community radio has become popular in recent years and it has opened a new arena for both the policy makers as well as grassroots people to be involved in the development process of their community. There are about 17 Community Radios broadcasting 135 hours programmes in a day across the country. The Community Radio can help us in addressing social, economic, cultural, educational, health, water and sanitation and disaster related issues more effectively and strategically. In order to highlight the importance and effectiveness of community radio for the community development of Bangladesh, this study has been conducted based on the secondary data. This is a group effort that has become successful by the co-operation of many individuals and institutions. Access to Information (a2i) Programme would like to express sincere gratitude to Monisha Mohonto, Project Focal and Bakul Mohonto, Program Assistant, BTV for introducing such an innovative project. As this is a new concept, there is no significant study has been conducted. Therefore the study has been directed to explore the importance of community FM radio in Bangladesh particularly in remote and rural areas.
\end{abstract}

Keywords: Community radio, Community Development, disadvantaged and vulnerable group, Remote and rural areas.

\footnotetext{
${ }^{1}$ Results Management Expert, Access to Information (a2i) Programme, Prime Minister's Office, Dhaka

${ }^{2}$ Research and Documentation Expert, Access to Information (a2i) Programme, Prime Minister's Office, Dhaka

${ }^{3}$ Research Assistant, Access to Information (a2i) Programme, Prime Minister's Office, Dhaka

${ }^{4}$ Research Assistant, Access to Information (a2i) Programme, Prime Minister's Office, Dhaka

${ }^{5}$ Research Assistant, Access to Information (a2i) Programme, Prime Minister's Office, Dhaka
} 


\section{Introduction and Background}

Community radio plays a vital role in the communications of a country. Community radio mainly serves a definite community and is a form of public-service broadcasting. It reflects the culture, ideology and thoughts, norms and values of a particular community. Community radio as the media of citizens of a particular community has become popular and new opportunity for both the media practitioner and grassroots people. Community radio helps to avail utilities and amenities for various development aspects of our society like education, health, water and sanitation, protection from natural disasters, address social issues at the community level and connect rural population with the government. It can be useful for the development of a particular target group like elderly, women and children.

Community radio helps to ensure people's right to information and community participation by expressing the voice and thoughts of grassroots people in the development process. Moreover, the United Nations, the Organization of American States, the African Commission on Human and People's Rights, and prestigious economists such as Amartya Sen, Joseph Stieglitz and Jeffrey Sachs, among others, have recognized the relationship between sustainable development and freedom of expression, reflected in a pluralistic and independent media sector (Buckley, 2008).

On March 8th, 2008, the Government of Bangladesh (GoB) has given approval of the "Community Radio Installation, Broadcast and Operation Policy". The principle purpose of the policy is to open up the radio spectrum to community broadcasting for exploring the potentialities of community radio. As GoB is emphasizing decentralization of media which has been reflected in the issuing of licenses for community broadcasting and Policy, as a way to facilitate and encourage people's privileges, in order to build a platform for community-level communication and sustainable development, through the accumulation of communities' energies, views and thoughts, initiatives, and resources. The initiatives of the Government to achieve the Right to Information Act 2009, Vision 2021, and the Millennium Development Goals (MDGs) have been considered in articulating the national strategy (Ministry of Information \& Ministry of Cultural Affairs. Government of Bangladesh. Dhaka. 2012).
Earlier, in the $1^{\text {st }}$ phase on 22 April, 2010, Ministry of Information has given approval to 14 community radio stations. Presently, 14 community radio stations have directed to a new era by rural broadcasting within a listeners' community of 4.6 million of 13 Upazila of the country. These programs focus the views and thoughts, rights and scopes of the disadvantaged community people (BNNRC, 2015).

Community radio can facilitates the disadvantaged and vulnerable groups of the country by raising their voice, focusing their problems, expressing their modern updated ideas and thinking for the development of the whole nation. It can play a significant role for the rural development of third world countries like Bangladesh through emphasizing agriculture, education, health and sanitation, recreation and social problems of a target community.

Radio is not a recent origin. People are acquainted with commercial radio and public-radio. Community radio can emerge a new era of communication for the rural people in Bangladesh. There is a lack of effective mass media for the rural disadvantaged population of Bangladesh. Commercial radio does not focus on the views and demands of local rural population. Besides, programmes and contents of commercial radio are not community people oriented rather encourage the western culture. Community radio falls under the community broadcasting category. Community radio is that kind of radio which is owned and controlled by a community and always broadcast those programmes which are related to that community interest. Numbers of community radio are not sufficient in Bangladesh to represent the interest of local rural population. Considering this drawbacks, this analysis titled "Role of Community Radio for Community Development in Bangladesh" has been conducted.

\section{Objectives}

The main objective of this analysis is to explore the importance and effectiveness of community FM radio in Bangladesh especially in remote rural areas. On the basis of the general objective, this analysis has following specific objectives;

- To analyze the effectiveness of community FM radio programs

- To know about the forms and features of community FM radio

- To explore the development and need of community FM radio in Bangladesh 
- To explore the opportunities of establishing community FM radio station

- To assess the need of setting up community FM radio station.

\section{Methodology}

This context analysis was elaborated using secondary data collected from national and international literature, journals, books, articles etc. These secondary data have been reviewed for understanding the comprehensive picture of community radio in Bangladesh especially for the marginalized population.

\section{An Overview of Community Radio}

\subsection{Community and Community Radio}

Community refers to a group of people with common characteristics or interests living together within a larger society. In other word, the term 'community' can be defined as a condition in which people find themselves engaged in interwoven and meaningful relationships with their fallows (Mtimde et al. 1998). A 'community' is considered to be a group of people sharing some familiar characteristics and or traits such as sharing a common geographical area i.e. a specific city and town, village; sharing of economic and social life through business and trade, exchange of goods and services among themselves (BNNRC, 2010).

In relation to community radio, the term 'community' refers to a collective or a group of people sharing common characters and/or interests. The term 'community' can either be defined as:

- a geographically based group of persons and/or

- a social group or sector of the public who have common or specific interests (Mtimde et al. 1998).

Community radio, as distinct from commercial and public service broadcasting, serves to bring local level small communities together, focuses on general public's day-to-day concerns and helps in realizing local demands and aspirations. In this sense, it aims to enrich the livelihood of the local people, through the content that is created by the people and for the people of the community (Wadia, 2007).Community radio is also defined as non-profit agency which is considered to serve specific local communities; thereby broadcasting programmes and contents which are relevant to the community and with organizational structures that represent the community the radio station work for (Fleming, 2002).

\subsection{The Evolution of Community Radio}

"Community radio is a social process and event in which members of the community associate together to design programmes and produce and air them, thus taking on the primary role of actors in their own destiny, whether this be for something as common as mending fences in the neighborhood, or a community-wide campaign on how to use clean water and keep it clean, or agitation for the election of new leader...Community radio is most relevant to a group of people who live and act as a community, and this could be several families, several neighborhood, or even several villages or communities, but the important thing is that they interact."

Carlos A. Arnaldo

The flourishing process of today country community radios has begun some 50 years ago in Latin America where the stimulus for these first experiences was poverty \& social injustice. Among these two, one had begun in Bolivia in 1947 which is known as the Miner's radios and another in Colombia in the same year, known as Radio Sutatenza / Accion Cultural Popular.

These experiences set a trend, even if today's concept of community radio has evolved considerably. For example, the Minors Radio in Bolivia was working in the decades of inner conflict between Marxism and capitalism. Thus, their main focus was to bring together the community of miners to combat for improved and better working environment. They considered Radio Sutatenza /ACPO in Colombia, although enthused by the endeavor of supporting the community of farmers or peasants, was not owned or directly governed by them. A lot of feedbacks were considered from farmers and these certainly ensured the incorporation of the farmer demands and desires into the radio's contents and programming. But it was not similar to today's aim of community radio which is 'radio by the people for the people'.

Systematic efforts by Radio Sutatenza to educate community people by radio created a progress that "... spread and was later consolidated through ALER, the Latin America Educational Radio Broadcasting Association. Inter - linkage of radio and education was the main thrust to the concept of public service and 
marked the inception of community broadcasting media in Latin America (Fraser, 2001).

Though it started in Latin America, it was in Europe where community radio first becomes a fundamental public phenomenon. In the 1960 - 70's when "swashbuckling entrepreneurs boarded the airwaves illegally and seizes as much of the audience as they could carry away from the treasure chest monopoly controlled by the state" were the first challenges to state public service broadcasting ( $T$. McCain and F. Lowe, 1990). In the West, these stations became able to motivate governments and national broadcasting systems to initiate local level community radio. After the ruin of the apartheid regime in South Africa, the establishment of community radio becomes a social movement in Africa (Moncef, 1998).

In many parts of the world (e.g. miners, missionaries and democracy movements), community radio is persuaded by the pressure groups. Besides, initiatives have been taken by international agencies such as UNESCO and other external donors to help get community radio off the ground. And in some cases, community radio services are introduced by national broadcasting organization (Fraser, 2001).

\subsection{Forms of Community Radio}

As community radio prepares and broadcasts programmes for the rural particular community, so it can also be specified to a target population. The historical philosophy of community radio is to make use of this means as the voice of the disadvantaged group, the representative of exploited people and generally as a tool for progress and improvement.

\section{i. The Power of Radio}

Radio is the most accessible mass medium of communication in use. And community radio is a crucial communication tool that is easy to run and maintain. It can capture more people, literate or illiterate at a time and also have lower cost than the community video, newspaper or television, particularly in developing countries.

Community radio can play a vital role in development and democratization by:

- Facilitating local communities to share their own understandings and to critically examine social issues, practices and policies affecting their lives and livelihood; and
- Enlightening and rising the communities around development initiatives and strategies that will result in a better life for listeners (agriculture, education, health and gender issues, disaster and environmental degradation, issues of local government, peace keeping etc.) (Mtimde et al. 1998).

\section{ii. Ownership and control}

Ownership and control of a community radio are usually the most important and crucial aspects in defining such a station. This can be decided through public and open meetings of communities where leadership of the station is elected into a Co-ordinate Committee of the station.

Decisions are taken in between annual general members meetings by the higher authority. Besides, higher authority fixes on the day to day running activities of the station and ensures the implementation of the policies. After a definite period (one or two year), decided by the community, these elected members of the management body arrange election for selecting future leaders.

\section{iii. Non-profit making aspect}

Community radio is a non-profit radio station and its main aim is the wellbeing of the local level community people. It produces program for the people of any certain geographical area and also represent their culture and views, thoughts and ideas etc. Also, community radio represents the society and culture of the community people of a particular area. Its objective is the development of that society, sharing their own culture, expressing their problems and limitations all around the world.

\section{iv. Community Participation}

The most important issue of a community radio is the community participation by which the community really owns and controls the station. The involvement of community members in many different ways that reflects the interest of the community it serves. The requirement of community participation ensures that members of the community are involved in the station with following activities:

- Election of Board Members

- Making policy for the station

- Management of the station

- Selection and provision of contents and programming

- Production of different programmes reflecting the community

- External representation of the station etc. 
While talking about Perspectives on Communication and Development in January, 1996 Heloise Henning and Eric Louw, DBSA, highlighted the importance of participation of community in giving information as well as in receiving information by saying - "the highest degree of community participation should be achieved not only in receiving information, but in providing the information that the community requires".

\section{v. Funding}

As the name refers, community radio is the asset of the community; it should be functioned by their own contribution, endowment and financial support. But as it plays significant role in achieving national development issues locally, Government might provide grant to operate community radio effectively (BNNRC, 2010). Funding for community radio services includes a range of sources, such as - public assistance, subscription fees of members, fundraising events, tariff and tax, funding, advertising income, etc. The viability and sustainability of community radio largely depends on such variety of funding sources (Mtimde et al. 1998).

\subsection{Distinct Features and Functions of Community Radio}

Community radio has the demonstration of different groups and concerns in the community and inclusion of disadvantaged and minority groups. Some distinct features are described below:

\section{i. The audience as protagonists}

The particular focal point of community radio is to make its audience the main standard-bearer, by their association in all portions of its management, content and program production, and by providing them with programming that will help them in the comprehensive development of the particular community.

\section{ii. A special slant on News, Entertainment and Education}

News on a community station is not an isolated story or event alone; rather, it aims to be a part of an ongoing and future process which supports change and development in the community. Education and entertainment are provided in a form that is collective cultural expression as well as sharing of experiences (Pate, 2013).

\section{iii. Principles of Public Access and Participation}

It is citizen's democratic right to get accurate, reliable and timely information. A community radio's broadcast pattern reaches all members of community it aims to serve; the community is free to comment and criticize. iv. Representation of Different Groups and Interests in the Community

Community radio broadcasts programmes that cater to vulnerable and marginalized groups in the community and encourage them to share their ideas and views on air. Disadvantaged and vulnerable groups in the community will be able through the broadcast of their programmes, problems and limitations, issues etc.

\section{v. Inclusion of Minority and Marginalized Groups}

The programmes of community radio encourage wide diversity of thoughts and views from different marginalized groups, such as women and youth or gypsy and dalit community. Besides, community radio promotes the cultural perspectives and interests of the minority groups (Fraser, 2001).

\section{vi. Promote Development and Social Change}

Sustainable development and positive social change of minority groups can be facilitated by community radio. It is community radio which can convey the sufferings and sorrows, difficulties and limitations of a community to the policy making authority. It can focus on the specific problems; arrange discussion on the remedies and mobile collective action.

\section{Community Radio in Bangladesh}

Though in a small number, community radio has started its journey in Bangladesh. It is needed to take initiative to increase the number of community radio in Bangladesh.

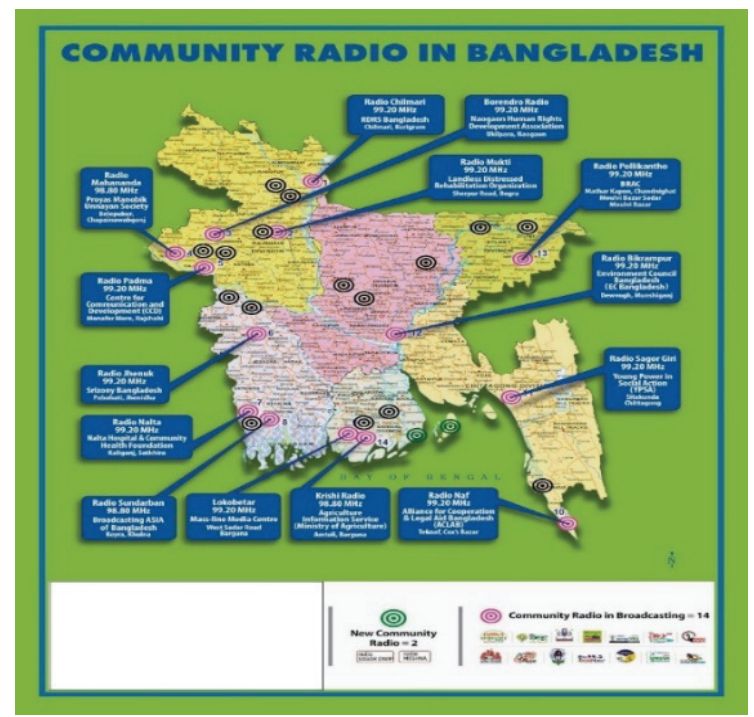

Figure 1: Community Radio in Bangladesh 
In the above mentioned figure, it is seen that there are 14 community FM radio stations in different location of Bangladesh. These stations broadcast local level programs and contents which reflect the culture, views and ideas, problems and sufferings.

\subsection{History of Broadcasting in Bangladesh}

The history of broadcasting refers, "After Guglilmo Marconi's discovery of wireless broadcasting in 1901, radio broadcasting was undertaken by amateurs. The first US commercial radio station KDKA of Pittsburgh, began operation in 1920" (Encyclopedia Britannica (India), 2005). The history of radio broadcast in Bangladesh dates back to the then British India and started broadcasting on 16 December 1939 as All India Radio at the old part of present Dhaka, the capital of Bangladesh. In 1971, Former Radio Pakistan changed its role as a front to assist the nation achieving its independence. Radio Bangladesh has been functioning as Bangladesh Betar (Radio) from all stations since the victory of Bangladesh on 16 December1971. Bangladesh Betar, only public radio transmission agency, has country wide broadcasting network programme with many FM channels to add to its operational efficiency.

5.2 Development of Community Radio in Bangladesh Community radio has been playing a significant role in raising the voice, thought, problems and issues of those people who do not have access to mainstream community and media. It facilitates the right to information, promoting the right to communication, assisting the flow of information. It also ensures the democracy in the country by expressing and sharing the views of rural communities. The linkage between community radio and community people is increasing day-by-day. In some areas, community radio has become a part of local-level people.

To introduce the community media in Bangladesh and giving focus on its vital role as representing the voices of the disadvantaged people, Bangladesh NGO's Network for Radio and Communication (BNNRC) has been struggling for about 12 years. As a result of it, the Community Radio Installation, Broadcast and Operation Policy 2008 has been announced by the Ministry of Information of the People's Republic of Bangladesh. In this context, Government of Bangladesh has approved 14 community radio stations for the first time in Bangladesh. The government enacted the Right to Information Act 2009to ensure the free flow of information to the people. Community radio stations are a strong march to give power to rural people also. It is really admirable for the Government to realize the importance of this traditional communication medium, radio which is older than 100 years but still very much useful for its easy userfriendliness and universal acceptability.

Table 1: History of Community Radio in Bangladesh

\begin{tabular}{|c|c|c|}
\hline Facts & Achievement & Year \\
\hline $\begin{array}{l}\text { Application for setting up of } \\
\text { Community Radio to the MOI } \\
\text { by MLMC. }\end{array}$ & $\begin{array}{l}\text { Started } \\
\text { journey } \\
\text { towards } \\
\text { establishment } \\
\text { of Community } \\
\text { Radio }\end{array}$ & 1998 \\
\hline $\begin{array}{l}\text { Advocacy Plan for Community } \\
\text { Radio entitled "Policy Advocacy } \\
\text { of CR in Bangladesh. }\end{array}$ & $\begin{array}{c}\text { Journey } \\
\text { Continued. }\end{array}$ & 1998 \\
\hline $\begin{array}{l}\text { Centre for } \quad \text { Development } \\
\text { Communication }(\mathrm{CDC}) \text { arranged } \\
\text { 1st National Mass Media } \\
\text { Conference }\end{array}$ & $\begin{array}{c}\text { Journey } \\
\text { Continued. }\end{array}$ & 1999 \\
\hline $\begin{array}{l}\text { Established Bangladesh NGOs } \\
\text { Network for Radio and } \\
\text { Communications (BNNRC) to } \\
\text { continue advocacy programme } \\
\text { with other } \text { concerned } \\
\text { organizations for Community } \\
\text { Radio. }\end{array}$ & $\begin{array}{c}\text { Journey } \\
\text { Continued. }\end{array}$ & 2000 \\
\hline $\begin{array}{l}3 \text { day Round Table on } \\
\text { Community Radio organized by } \\
\text { BNNRC, MMC, Focus, YPSA } \\
\text { and Voice. }\end{array}$ & $\begin{array}{l}\text { Advocacy } \\
\text { continued. }\end{array}$ & 2006 \\
\hline \multirow[t]{2}{*}{$\begin{array}{l}\text { Community Radio Awareness } \\
\text { Workshop jointly organized by } \\
\text { Commonwealth Educational } \\
\text { Media Centre for Asia } \\
\text { (CEMCA), BOU, Development } \\
\text { Research Initiative (DNet) \& } \\
\text { BNNRC. }\end{array}$} & $\begin{array}{l}\text { Initiative to } \\
\text { develop } \\
\text { Human } \\
\text { Resource for } \\
\text { Community } \\
\text { Radio on } \\
12^{\text {th }} \text { March, } \\
2008\end{array}$ & 2008 \\
\hline & $\begin{array}{c}\text { The } \\
\text { Community } \\
\text { Radio } \\
\text { Installation, } \\
\text { Broadcast and } \\
\text { Operation } \\
\text { Policy-2008 }\end{array}$ & 2008 \\
\hline
\end{tabular}

(Source: monjur.doc.paper.pcf5)

Mass people awakening programmes and movements along with those advocacy programmes organized by national and international NGOs, pro-active patterns and associations have support the government to give approval and implement the policy. 


\subsection{Need for Community Radio: Bangladesh Context ICT, a2i and Community Radio}

There is huge importance of ICT in every sector of development. Government of Bangladesh is trying to introduce ICT in every sector through its "Access to Information (a2i) Program".

Ministry of Information and a2i programme of Prime Minister's Office signed a MoU among 14 community radios on 27th May, 2014 where the main objective is to support the community radios stations considering the existing limitations, obstacles and challenges and encourage the vision of Digital Bangladesh to the rootlevel or local level community.

\section{Service for Root level Population}

Community radio has been established mainly for local level rural population. Main target group of community

radio are the general villagers who I are the listeners of radio. Community radio will create awareness among the villagers about social issues and will also entertain them. It will give information regarding agriculture, purchase and production, rainfall updates, emergency alerts etc.

\section{Minimizing the Crime}

Community radio can minimize crime from two perspectives. Firstly, after committing crime, the community people will inform their community radio about the crime and then this information would be shared to other people of other areas, police and other law enforcing agencies. If a murder is happened in one part of an area and the police station is in the other part, community radio can inform the law enforcing agencies as soon as they get the news.

\section{Education for All}

Community radio can perform a significant role for educating the illiterate section of our country. Programmes and contents of community radio are community-oriented as well as life oriented which are important elements for understanding local issues and problems. Besides, school and college curriculum based education programmes can be broadcast for drop-out students. Also, classes and lectures can be broadcast live for working children. Education programmes in the form of recreational programme in community radio can attract the children.

\section{Information for Adolescents}

During adolescents periods, young boys and girls in our country cannot share their problems and issues to elders. In this context, community radio can help them through providing necessary information and services. Community radio can create awareness and highlight the duties and responsibilities of guardians towards the problems in adolescent periods.

\section{Information about Agriculture}

In the modern civilized world, farming is based on technology. Though our country has been using modern technology but the proportion of using modern technology is not up to the mark. As a result, the production is less than other developed countries. Community radio can broadcast informative programmes for farmer. It can be the real friend of the village farmers. Besides, marketing and purchasing of seeds and saplings can be easier through the informative programmes of community radio. It will help the farmers to get information about different methods and strategies of seed and sapling preservation.

\section{Services for Oppressed Women and Unemployed Youth}

Women are one of the vulnerable groups of our society. In most of the cases, illiterate women are oppressed by men for dowry and other reasons. Immediate Legal aid services can save those women from such oppression. There are many government and non-governmental organizations in Bangladesh who are working for promoting women rights. Both the literate and illiterate women of our country are not aware about their rights and services. Even they do not know where to go for getting support. Community radio can perform a significant role in these regard. Community radio can broadcast awareness programs for women and inform those women about the sources where to go for getting legal aid services. Besides, employment opportunities for oppressed women can be ensured by the programmes of community radio. A mother can learn personal hygiene and maintain good health of her children through the educative programs of community radio. 


\section{A. A. Khan / Role of Community Radio for Community Development in Bangladesh}

Moreover, community radio can provide unemployed youths with the information of working facilities like where are job opportunities for them, how to cultivate vegetables and fish, where to get bank loan for small entrepreneurship, where to purchase and sell required products etc. Community radio can remove the unemployment problem from our society.

Community radio is capable of connecting its distinctive nature of raising surpassed voices, practices and traditions. As a tool for social change, community radio has several advantages over the other media:

(i) It allows true participatory communication which is essential for sustainable development;

(ii) It serves a specific community or group (marginalized or vulnerable);

(iii) Its programmes and contents are relevant to the community;

(iv) It is an ideal communication tool for the illiterate population; and

(v) It is cost-efficient in terms of investment which will facilitate its sustainability.

It is expected that the convergence of community radio with Internet is providing new content, new services and new networking opportunities for the community members (Virtanen: 2005:1).

\section{Limitations}

The limitations of this study are as follows:

i. Unavailability of primary data to understand the present scenario of community radio in Bangladesh

ii. The inadequacy of secondary data for better evaluation

\section{Recommendations}

Hard to reach areas will be benefited by the programmes of community FM radio stations. Hard to reach people/community of Bangladesh can be developed and express their problems and demands through establishing community radio station that will ensure their socio-economic development.

However, to spread the blessing of community FM radio, Ministry of ICT of the GoB needs to:

- Train-up people to manage the system and create contents/programs which will express the views and sufferings of marginalized and vulnerable groups

- Ensure access and participation, diversity, independence and locality, so that member of marginalized group can express their problems and difficulties through community FM radio station
- Ensure multi-use of community FM radio i.e. spreading information of education, health and other nationally important issues.

\section{Conclusion}

Radio is popularly known as the mass media which has the maximum number of listeners. It has significant effect on the societal condition of our country till now. In today's world, people are acquainted with FM radio and community FM radio has the capacity to reach the local level rural population. For ages, there is a criticism in context of presented radio broadcasting environment in Bangladesh that air broadcasting has been strongly influenced by political forces. Since the starting journey of Radio in Bangladesh, it has been largely used for state supported propaganda. Though there are some commercial radios' but community radio is yet to be legitimated in Bangladesh. Besides, professional or commercial broadcasters believe that community radio will lessen the superiority of commercial radio in Bangladesh. Also, they think that their stations will lose listeners if community radio can be established everywhere. Community FM radio can focus the voice of vulnerable and marginalized population of our community, facilitate rural development and agricultural promotion, ensures local level good governance and accountability, disaster preparedness and management, ensuring gender equality, community empowerment as well as protect the local and community culture. Community FM radio station can be a blessing for local level population. Community FM radio will help, inter alia;

- To facilitate the social advancement especially for hard to reach areas

- Setting up more community FM radio station is necessary to spread the voice of marginalized and vulnerable group to the policy makers, social scientist and others

- To build up awareness about social issues, social problems like child marriage, poverty and unemployment problems can be ensured through community FM radio station

- Any area based upcoming natural calamity could broadcast towards the focused group of people

- Education and training could be provided easily

- Community broadcasting would be sustained by the principles of access and participation, volunteerism, diversity, independence and locality. 


\section{References}

1. About Community Radio: Local National Regional \& Global, [online] Available at: http://www.bnnrc.net/ network/communityradioinbangladesh/community-radio (Retrieved on: 10 December 2015).

2. Britannica Ready Reference Encyclopedia. (2005) Encyclopedia Britannica (India) Pvt. Ltd. New Delhi, India, Volume-1 p. 84. monjur.doc.paper.pcf5.

3. Buckley, Steve, "Community Broadcasting: Good practice in Policy, Law and Regulation" Paper prepared for UNESCO for World Freedom Day 2008: 2.

4. Fleming, Carole. (2002) The Radio Handbook, Routledge; $2^{\text {nd }}$ Edition, pg. 176.

5. Fraser, Colin and Estrada, S. Restrepo. Community Radio Handbook. UNESCO, 2001.

6. General Guideline and FAQ. (2010) Community RadioSet-up in Bangladesh. Bangladesh NGOs Network for Radio and Communication.

7. Moncef M. Bouhafa. (1998) Child Survival and Broadcasting-opportunities and Challenges. International conference on Broadcasting for Child Survival, Voice of America/USAID. Washington.
8. Mtimde, L., Bonin, M.H., Maphiri, N., Nyamaku, K. (1998) What Is Community Radio? AMARC Africa and Panos Southern Africa in collaboration with IBIS/Interfund and WACC.

9. National Strategy for the Implementation of Community Radio Installation, Broadcast and Operations Policy in Bangladesh. Ministry of Information \& Ministry of Cultural Affairs. Government of Bangladesh. Dhaka. 2012.

10. Pate \& Abubakar. (2013) The Struggle for Community Broadcasting in Nigeria. Jurnal Pengajian Media Malaysia / Malaysian Journal of Media Studies. University of Maiduguri, Borno, Nigeria. Vol. 15, No. 1.

11. T. McCain and F. Lowe. (1990) Localism in Western European Broadcasting. Journal of Communication. Vol. 40-1.

12. Virtanen, T (2005). "Community Radio and Video Narrow-casting", Workshop presentation,AIBD/ UNESCO/ FES/ WRTVC Workshop on Citizens Media, Asia Media Summit-2005, Kuala Lumpur, Malaysia; monjur.doc.paper.pcf5.

13. Wadia, Angela. (2007) Broadcast Management in India: Major Guidelines and Policy Frameworks, Kanishka Publishers Distributors, pg.95. 